\title{
12
}

\section{Revising a Combined Sewer System Design for Improved Results}

\author{
Larry J. Witt, Philip N. Brink, Tarlochan S. Bhullar and \\ Bharat R. Doshi
}

A new combined sewer system was designed for an existing sewer district located in the city of Detroit to address chronic basement flooding. The existing sewer system generally consists of sewers located in alleys behind homes, picking up both sanitary flows from the homes and storm flows from catch basins located in the streets. The proposed plan called for locating new sewers down most of the streets and bringing the existing house leads from behind the houses around front to connect to the sewers in the streets. The new system proposed consisted of a complete replacement of the existing system; it did not consider potential use of portions of the existing system to economize on cost.

Upon further review by the Detroit Water and Sewerage Department (DWSD), this approach was not considered to be feasible due to the difficulty of being able to relocate the house leads. In many cases, there is not enough space to work between homes to reroute the house leads. In addition, such work would require construction on private property which would be quite disruptive to the neighborhood and community life, and furthermore, would not qualify for State funding.

The city revised the proposed new sewer system design to incorporate the existing system to the extent possible while providing the desired level of service for the district. Specifically, where possible, the revised design was configured to intercept a sufficient number of catch basins in the streets

Witt, L., P. Brink, T.S. Bhullar and B.R. Doshi. 2009. "Revising a Combined Sewer System Design for Improved Results." Journal of Water Management Modeling R235-12. doi: 10.14796/JWMM.R235-12. (C) CHI 2009 www.chijournal.org ISSN: 2292-6062 (Formerly in Conceptual Modeling of Urban Water Systems. ISBN: 978-0-9808853-2-3) 
to prevent storm flows from surcharging the sewers collecting sanitary flows from the homes which are predominately $12 \mathrm{in.}(300 \mathrm{~mm})$ laterals located in alleys behind the houses. Approximately 50 to $75 \%$ of the storm flows, depending on the area, will be effectively intercepted with the revised design which proved to be sufficient to prevent surcharging within $8 \mathrm{ft}(2.4 \mathrm{~m})$ of ground level. Thus, the revised design will be able to provide the required level of service for the Oakwood District at a significant cost savings to the original proposed design.

\subsection{Background}

The DWSD serves an area in southeastern Michigan with both water and sewer services. The sewer system encompasses an area of approximately 900 square miles $\left(2300 \mathrm{~km}^{2}\right)$ whereby $70 \%$ of the system is separate and $30 \%$ is combined. The capacity of the WWTP is 1700 million gallons per day (mgd) $(74,000 \mathrm{~L} / \mathrm{s})$ primary and $930 \mathrm{mgd}(41,000 \mathrm{~L} / \mathrm{s})$ secondary treatment. The City of Detroit is a combined system whereby the wet weather overflows travel by gravity (for most of the city) to either the Rouge or Detroit rivers. An agreement is in place between DWSD and the State of Michigan Department of Environmental Quality to capture and treat a majority of the overflows prior to being discharged to the rivers or being returned to the system for treatment. If the storage capacity of the Combined Sewer Overflow (CSO) facility is exceeded, the treated effluent will be discharged to the river. If the storage capacity is not exceeded (most rainfall events) the stored combined sewage will be returned to the sewage system for treatment at the wastewater treatment plant. The agreement maintains that these CSO basins or alternative control facilities will be in place within the next 20 years more or less. It is noted that the agreement is extensive. DWSD has 76 outfalls and each outfall falls into a category for various levels of capture and treatment.

The Oakwood Sewer District is located in southwest Detroit as shown in Figure 12.1. It covers 1520 acres (600 ha) and has a population of about 11,400 . It does not have a gravity outlet to the WWTP or to the overflow on the Rouge River. All wet and dry weather flows must be pumped by the existing Oakwood pump station. The dry weather (sanitary) flow is pumped to the WWTP and the wet weather flow is pumped to the Rouge River, as shown in Figure 12.2. The dry weather flow for the district ranges from 4.5 to $9 \mathrm{cfs}(254$ to $127 \mathrm{~L} / \mathrm{s})$ throughout a typical year.

The Oakwood District (district) has a history of basement flooding problems. Causes are mainly due to the existing pump station capacity and 
the catch basins in the area being connected to $12 \mathrm{in.}(300 \mathrm{~mm})$ and $15 \mathrm{in}$. (380 $\mathrm{mm}$ ) laterals located behind the houses. The existing pump station capacity is $500 \mathrm{cfs}(14,000 \mathrm{~L} / \mathrm{s})$ and the new pump station capacity will be $1650 \mathrm{cfs}(47,000 \mathrm{~L} / \mathrm{s})$ which is the predicted peak combined sewer overflow determined in prior studies using the design rain event of a $10 \mathrm{y}$ storm (1.8 in. $/ \mathrm{h} 45 \mathrm{~mm} / \mathrm{h}$ ) for the Detroit area.

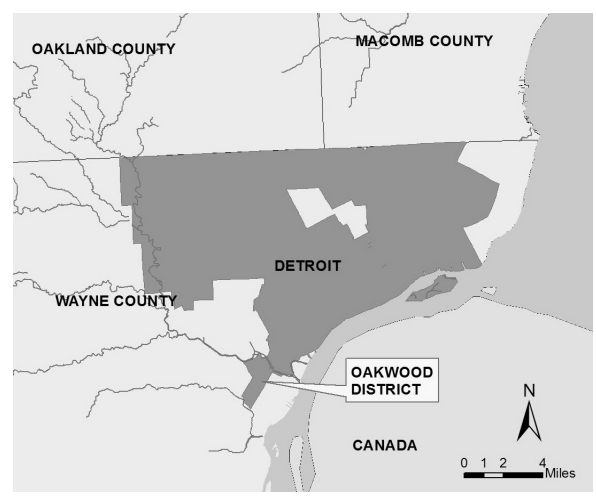

Figure 12.1 Oakwood sewer district location in southwest Detroit.

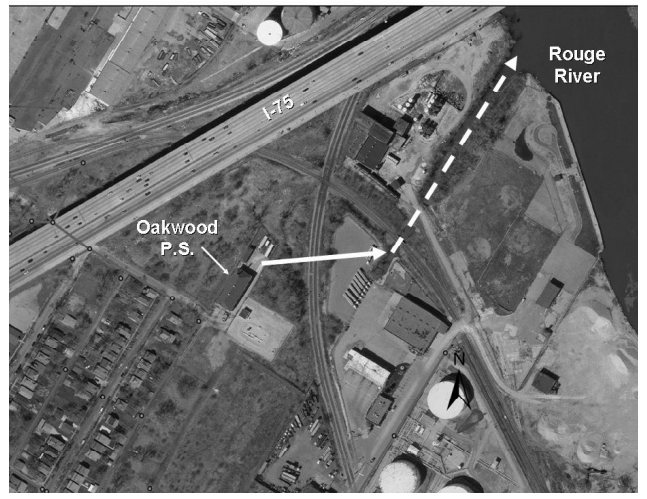

Figure 12.2 Location of Oakwood pump station and discharge to Rouge River.

The Oakwood District Storm Relief program has two aspects; a new pump station with retention basin and a new sewer relief system. The pump station/basin is under construction and is being handled by others. Figure 12.3 shows the site. The focus herein is the new sewer relief system aspect of the program. 


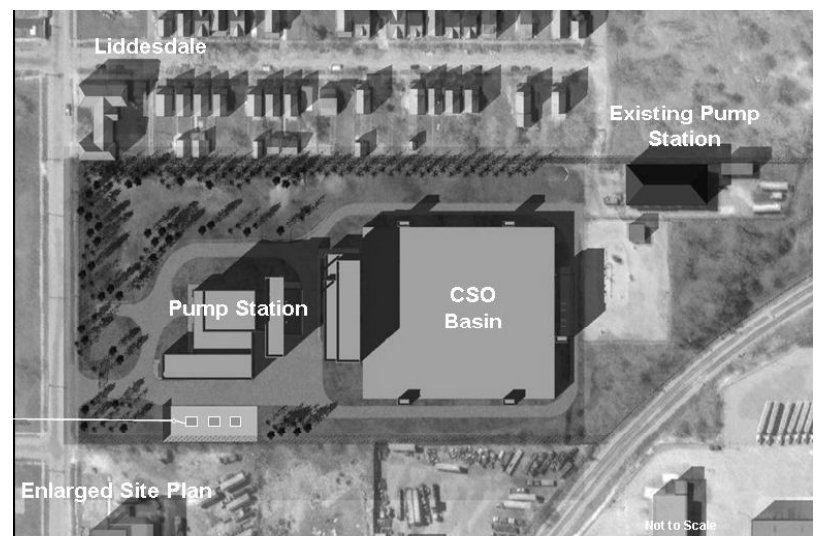

Figure 12.3 Schematic of new pump station and CSO basin.

\subsection{Prior Studies}

Reports and memos of basement flooding in the district have been on file for a number of years. Various relief alternatives have been investigated including:

- sewer separation,

- relief sewers,

- catch basin restriction,

- combined separation with relief sewers,

- increased pump station capacity, and

- increased pump station capacity with relief sewers.

For the original basis of design (BOD) as well as the revised BOD as discussed herein, the selected alternative was increased pump station capacity along with relief sewers.

\subsection{Oakwood Model Formulation}

The sewer system in the Oakwood District was not originally designed by DWSD, as the district was annexed to Detroit after the system was already put in place in the 1920s. Due to ongoing flooding issues and complaints, DWSD started analyzing the district with backwater curves and other analyses in the 1970s. These analyses provided the framework for the model 
used here. In the 1980s and 1990s, DWSD developed the Greater Detroit Regional Sewer System (GDRSS) Model of the entire DWSD service area (TenBroek, 1999). This model had very limited detail in the Oakwood district; however, the runoff parameters as developed for the GDRSS Model were incorporated into the Oakwood Model. These parameters were developed using eleven detailed study sites to establish directly connected impervious area percentages, infiltration rates and characteristic subcatchment widths, and these parameters were incorporated in the model used for both the original and revised BOD models. The average directly-connected impervious area (DCIA) used for the residential areas of the district was 38\%.

The model that was generated under an earlier contract (April 2001) had about 80 pipes (smaller size lateral sewers were not included), and it used six rainfall events for calibration. The size of these events ranged from 0.86 in. to 1.94 in. (22 to $49 \mathrm{~mm}$ ), with durations of 2 to $8 \mathrm{~h}$. The model was later expanded and configured for both existing conditions and for the original BOD. This model had about 900 pipes, and it was calibrated using two of the rainfall events that were used for the earlier model. The current model used for the revised BOD discussed herein used the existing conditions model as its starting point. The model now has over 1,000 pipes to represent the revised BOD conditions.

\subsection{Original Basis of Design}

A new sewer collection system for the tributary service area was designed by consultants. The new system consisted of a complete replacement of the existing system; it did not consider potential use of portions of the existing system to economize on the cost for this project. The proposed plan called for locating new sewers down most of the streets and bringing the existing house leads from behind the houses around front to connect to the sewers in the streets. Upon further review by DWSD, this approach was not considered to be feasible due to the difficulty of being able to relocate the house leads. Furthermore, the design did not take into account that the new sewers would be located where large sewers (4 to $10 \mathrm{ft}(1.2$ to $3 \mathrm{~m})$ in diameter) already existed. The new sewers were set at the same approximate depth ( 25 to $45 \mathrm{ft}$ ( 8 to $14 \mathrm{~m}$ ) which would have been too deep for open cut construction) as the proposed sewers. When queried upon how this typical situation throughout the district would be handled for construction, there was little to no response from the design consultants. It was then decided to revise the basis of design. 


\subsection{Approach for Revised Basis of Design Development}

The design consultants provided DWSD with two models; one for existing conditions and one for revised conditions (original BOD). It was decided to use the existing conditions model as the basis for our revised design and add new pipes as needed to develop a revised BOD model. The original BOD model had a concept of providing a large tunnel sewer down a road that divided the community basically in half (except for the northwest section), and this concept remained in the revised BOD.

Both the existing-conditions model and the original BOD model as delivered to DWSD had to be modified in order to make them work. Both models were in XP SWMM format and would not work in the version of SWMM that was in our possession (SWMM 4.4H-2002). In order for a XP SWMM model to be converted to EPA SWMM format using an available converter, a DAT file produced by an XP SWMM simulation is required. This file was not provided; therefore, both models were modified (converted) manually line by line. Both models also required a number of minor adjustments before they would run without errors. Time steps were adjusted and pipe lengths were generally lengthened to better meet the courant condition. Inverts were then adjusted to keep the slope in line with the change in length. Nodes with flooding that seemed excessive were examined as well for potential error in the data or for the need to represent surface flooding by adding storage to the node.

The northwest area of the district drains via two major sewers, Sanders and Powell/Fort, as shown in Figure 12.4. These two sewers join on the west side of Fort Street, then cross under Fort Street, through a private property parcel, under a major railroad right-of-way, and then under a major interstate highway (I-75) before discharging at the Oakwood pump station. After it was decided to revise the original BOD to incorporate the existing system to the extent feasible, it had to be determined if these two sewers and the outlet sewer would have sufficient capacity once relief sewers were added to the existing sewer system in this area. If these existing two sewers and the outlet sewer could not take the additional flows that would be generated once the relief sewers were added, then a new sewer of approximately $6000 \mathrm{ft}$ $(1800 \mathrm{~m})$ of 5 to $8 \mathrm{ft}$ (1.5 to $2.4 \mathrm{~m})$ sewer as called for in the original BOD would need to be built along Sanders and Powell.

Before the computer models were available for this district, DWSD Engineering staff initially conducted hand calculations to evaluate the 
capacity of the sewers in the northwest section of the district, an area containing approximately 60 acres ( $24 \mathrm{ha}$ ). These calculations were based on the DWSD storm design criteria standardized methods that have been used by DWSD for years and consist of a combination of the Manning's equation and the Rational Method. These calculations were labor-intensive, but they did confirm results obtained later from the model simulations for the area. It is noted that the hand calculation method of the past was not used for design of an area that exceeded 100 acres (40 ha) for an individual detailed project. Larger areas in their entirety were evaluated for capacity restraints however. The Oakwood district exceeds 1400 acres (570 ha) and design changes could be dynamically reviewed in the model. This was not an option using hand calculations.

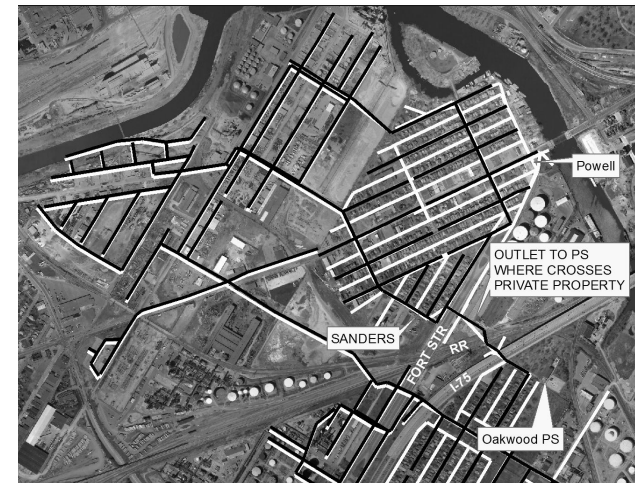

Figure 12.4 Existing Sewers (white) and original BOD sewers (black).

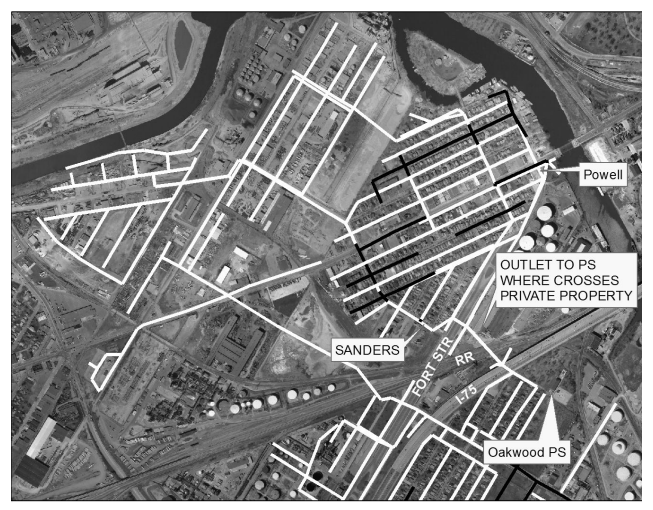

Figure 12.5 Existing sewers (white) with relief sewers of revised BOD (black). 
The new relief sewers were added to the model as shown in Figure 12.5, the runoff was redistributed and the existing pump station was removed. That is, the model was configured with a free discharge to represent the expected capacity of the new pump station being built. This concept was accepted as the revised pump station was designed to handle the 10 y $1 \mathrm{~h}$ storm. The results from this analysis showed that the flow from the northwest section could indeed be handled by the two existing sewers. Profiles showing the northwest sewer system hydraulic gradelines (HGLs) can be seen in Figures 12.6 through 12.9. Using the two existing sewers provided a major benefit to the project as it eliminated the need for a new sewer to be constructed under a major road (Fort Street), a railway, a freeway (I-75) and a large parcel of private property which has a large building adjacent/ over to planned construction.

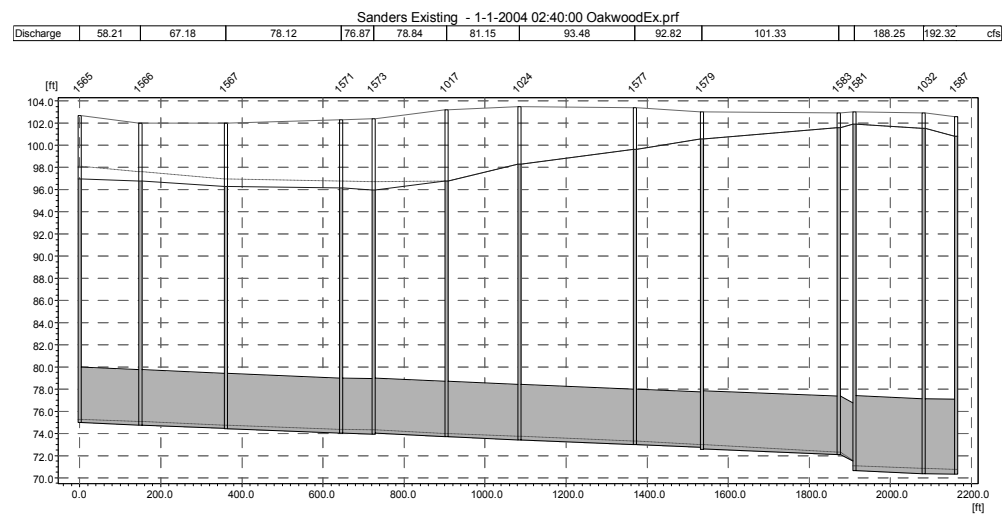

Figure 12.6 Sanders sewer existing.

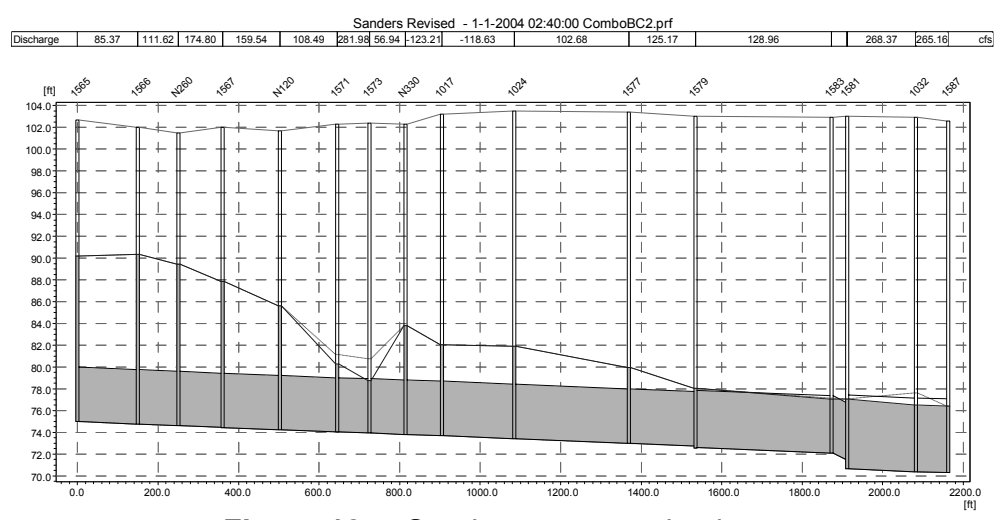

Figure 12.7 Sanders sewer revised. 


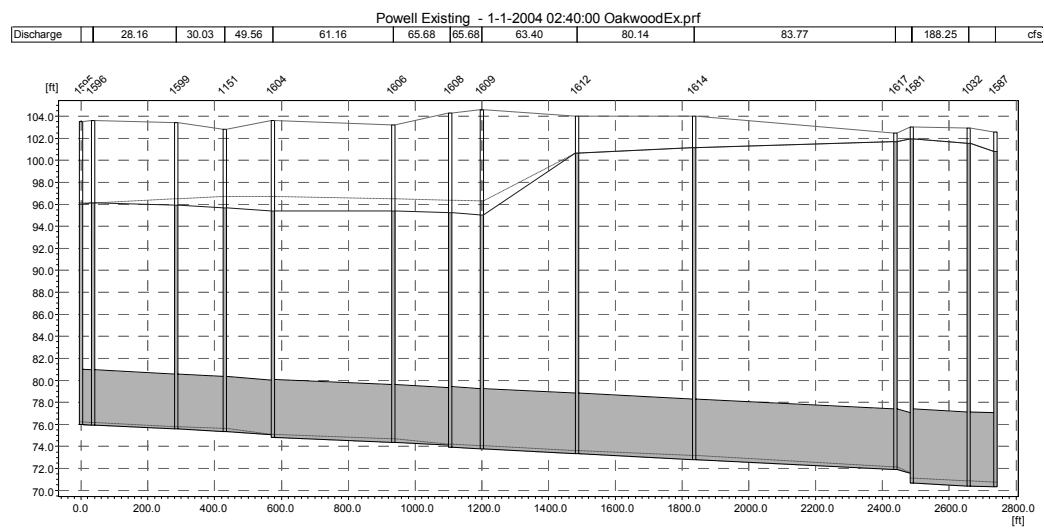

Figure 12.8 Powell/Fort sewer existing.

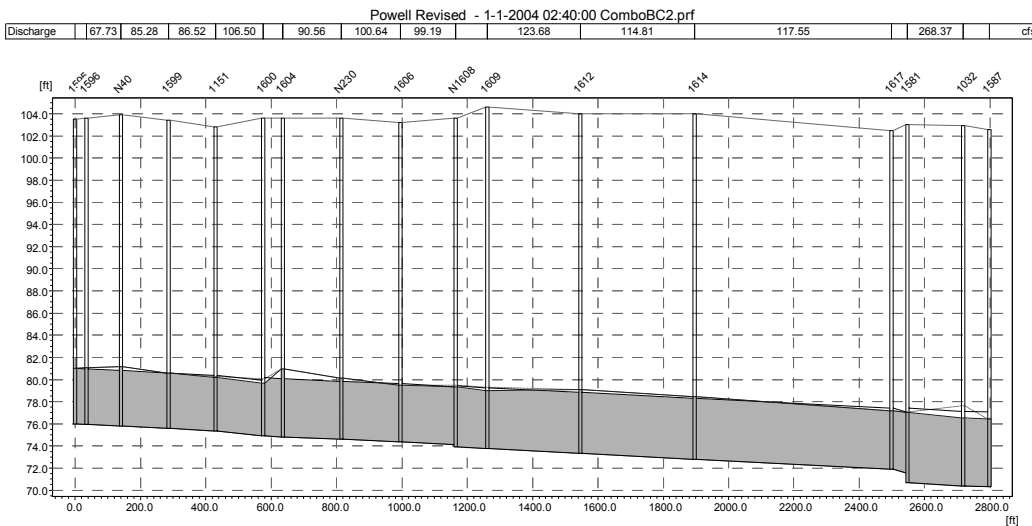

Figure 12.9 Powell/Fort sewer revised.

Once DWSD confirmed the operation and use of the SWMM Model for analysis of the district, the responsibility for developing a revised BOD for the rest of the district was divided between DWSD and CDM, as shown in Figure 12.10. DWSD was responsible for the western portion of the district and CDM was responsible for the eastern portion of the district. As some of the design proceeded in tandem, this approach required manually copying the added relief sewers from the one model to the other to produce a final model. This process allowed the project to meet required deadlines for the project. 
A number of tools were used to develop the revised BOD sewer system. These tools included:

- EPA SWMM 4.4 H

- DHI Mike View 2004

- $\quad$ ESRI ArcView 9.1

- Revised coordinates

- Catch Basin locations

- Viewing and location of layouts

- PCSWMM 2005

- ESRI ArcView 3.2 \& SWMM Tools

- generate shape files

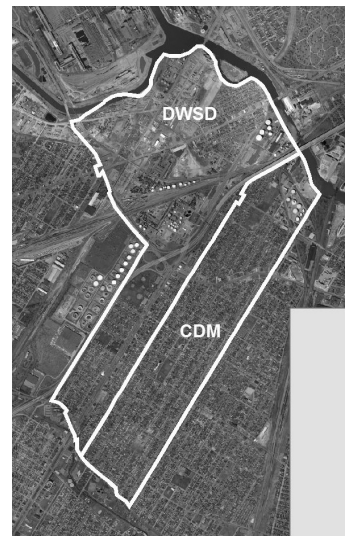

Figure 12.10 Area of responsibility in developing revised BOD.

The EPA SWMM 4.4H version of SWMM was used to model the hydrologic and hydraulic components of the district. Hydraulic results both in plan and profile were viewed using MikeView. The layout of the system was viewed using shape files in ArcView 9.1. The original design consultant provided shape files that included the pipes and manholes for existing and revised conditions, aerial photos and catch basin locations. PCSWMM was used to lay out the eastern portion of the district. The eastern portion involved adding new relief sewers and PCSWMM was helpful in being able to place sewers graphically and generating associated input data required for the model. The western portion drew upon the original BOD street locations except for the 
larger trunk sewers which were redesigned to drain more efficiently. ArcView 3.2 and SWMM Tools were used to generate shape files to reflect the updated sewer system.

\subsection{Analysis and Results}

The existing SWMM models for both existing and proposed conditions (original BOD) were collected. Other project related information such as aerials, sewer section maps, existing design drawings for the proposed system, location of flooding complaints, existing catch basins, house leads and utilities (electric, cable, telephone, etc.) considered in locating new sewers were also collected. It was decided not to use the original BOD model and instead add new relief sewers to the existing model for the reasons previously stated.

A desired level of service criteria for the district was established as maintaining the peak HGL experienced during a $10 \mathrm{y} 1 \mathrm{~h}$ design storm event $(1.8 \mathrm{in} . / \mathrm{h}(45 \mathrm{~mm} / \mathrm{h})$ below $8 \mathrm{ft}(2.4 \mathrm{~m})$ from the surface. The revised BOD largely meets this criterion, though there are several locations where the existing sewers are less than $8 \mathrm{ft}$ deep. In these cases, the sewer without any surcharging does not technically meet the criteria, though flooding of basements is not considered to be an issue for these special cases.

A $1 \mathrm{~h}$ duration for the design event was used as this duration is generally the critical duration for the local sewers. The $1.8 \mathrm{in}$. of rainfall was distributed over 3 min intervals using Intensity-Duration-Frequency (IDF) curves.

An example of the change from the original design to the revised design is shown for the southeast portion of the district in Figures 12.11 through 12.13. The existing condition is shown in Figure 12.11. As shown the catch basins are connected to the sanitary laterals that provide service to the homes.

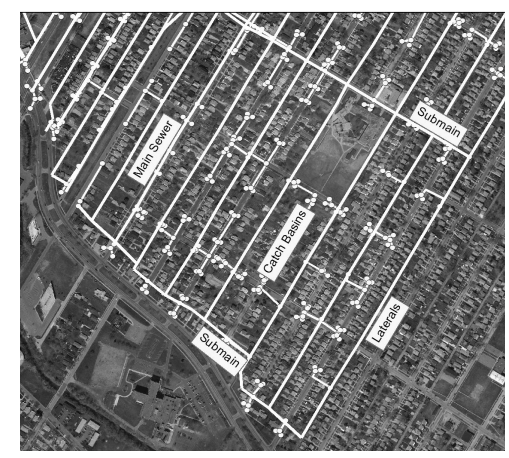

Figure 12.11 Existing sewers in southeast portion of the Oakwood district. 
The original BOD proposed new sewers down each street to collect the flows from the catchbasins, as shown in Figure 12.12. The existing submain and main sewers were also to be replaced.

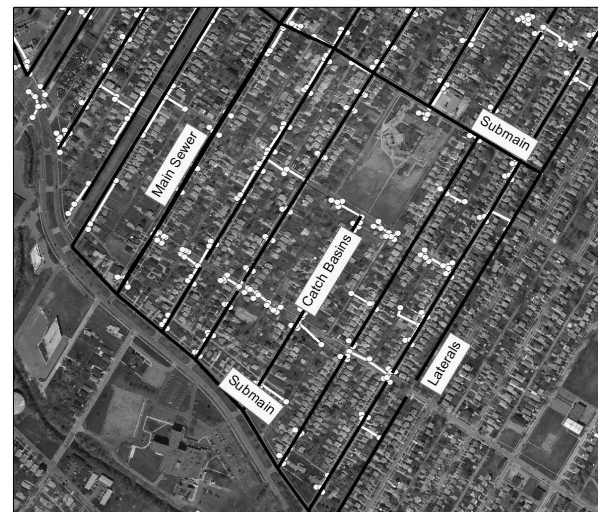

Figure 12.12 Original BOD in southeast portion of the Oakwood district.

An approach used here and elsewhere with success in the revised BOD was to provide what would be an equivalent of an additional submain that would be connected to some, but not necessarily all, of the catchbasins. This approach is shown in Figure 12.13. It should be mentioned that the original BOD did include a new main sewer in parallel with the existing Main sewer. This aspect of the original BOD was included in the revised BOD.

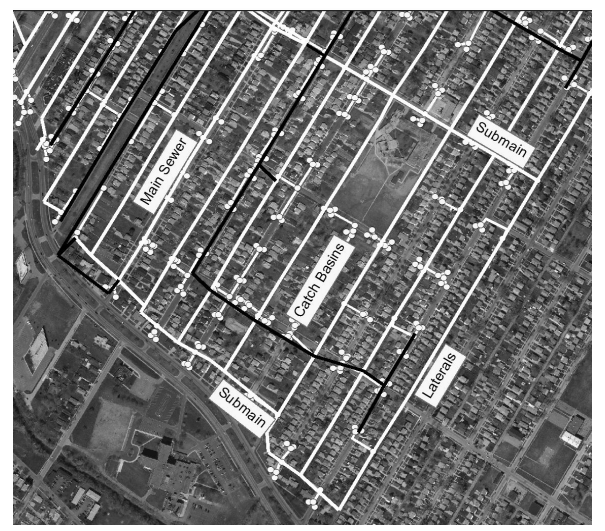

Figure 12.13 Revised BOD in southeast portion of the oakwood district (existing sewers shown in white with relief sewers shown in black). 
The impact of the new proposed pump station on the existing HGL was evaluated by setting the model with free discharge, as previously mentioned. The validity of this assumption was verified as the predicted flows for the proposed system never exceeded the capacity of the proposed station.

The judicious use of storage can help mitigate instabilities that can occur in some instances in an EXTRAN model; however, adding storage to nodes is a delicate matter. If storage is added at a location which has short pipes and connecting sewers, it can make the model more stable. If storage is added to a large sewer at a location where there is sufficient capacity, it can cause problems. Figure 12.14 shows an example profile where a high HGL occurs at a node where there are no connecting sewers or inflow from a subcatchment; that is, it was not a reasonable looking profile. A small amount of storage $\left(100 \mathrm{ft}^{2} / \mathrm{ft}\right)$ was added at a couple of key locations (the node locations changed based on model results and all the runs were not tracked precisely) to see if the apparent instability could be eliminated. The results, as shown in Figure 12.15, are much improved.

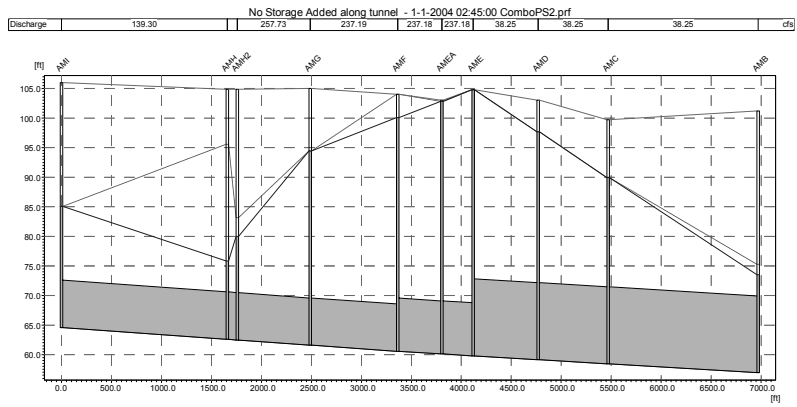

Figure 12.14 Results showing high HGL due to local instability.

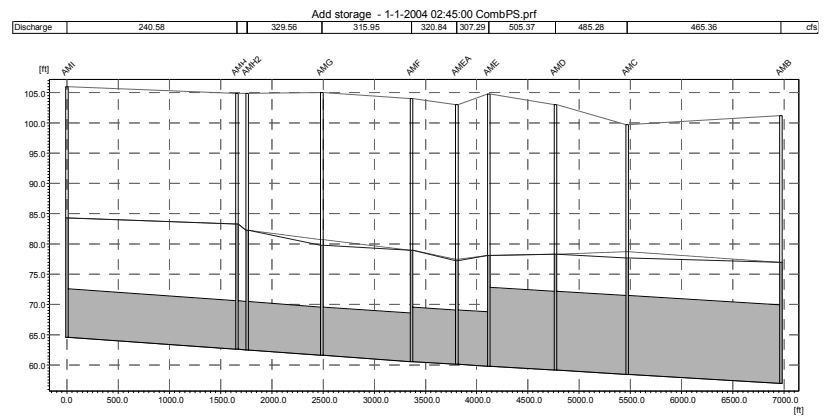

Figure 12.15 Results with storage added where needed for stability. 
The results of the revised BOD are compared to the existing conditions in Figure 12.16. In this figure, two schematics of the entire Oakwood District sewer system are shown for these two conditions. Nodes (manholes) where the model predicted HGL resulting from the $10 \mathrm{y} 1 \mathrm{~h}$ design event is less than $8 \mathrm{ft}$ from the surface are shown as black dots. Nodes where the HGL is more than $8 \mathrm{ft}$ below the surface are shown as grey dots. As can be seen, under existing conditions, virtually the entire system does not meet the design criteria set for this district. Under the revised BOD, the results are much improved. It is noted that the design criteria is not completely met as the sewer pipe in some locations is less than $8 \mathrm{ft}$ from the ground surface. Also, flooding was not addressed in commercial/industrial areas where no basements exist.
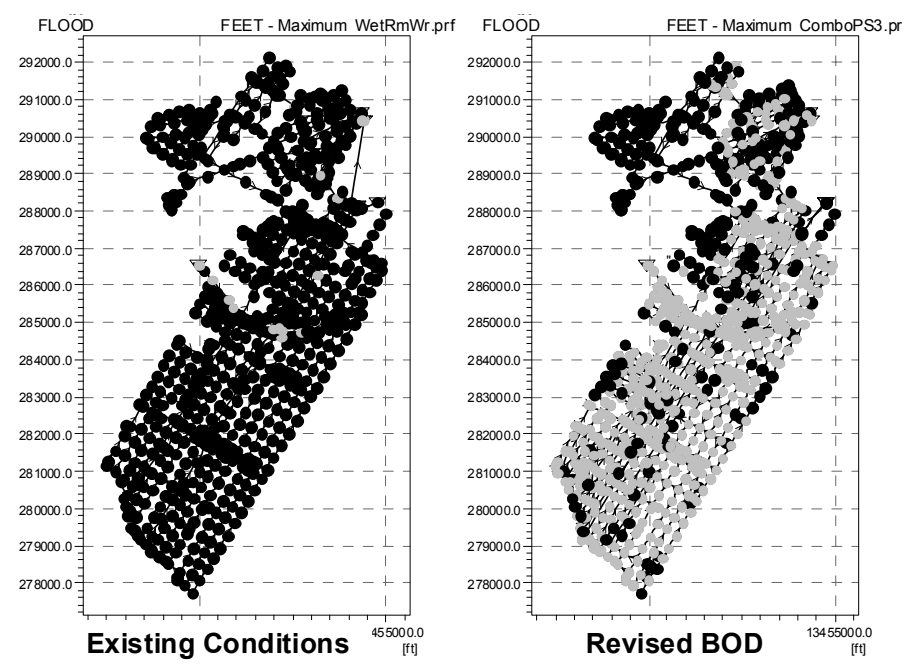

Figure 12.16 Comparison of HGL elevation for existing conditions and revised BOD (Black dots (nodes or manholes) indicate that the HGL is within eight feet of the ground surface, while gray dots indicate that the $\mathrm{HGL}$ is more than eight feet below the ground surface.).

\subsection{Conclusions and Lessons Learned}

The original BOD did not consider the use of the existing system and included 160,000 feet $(49,000 \mathrm{~m})$ of new pipe. The revised BOD made use of the existing system. It required only 60,000 feet $(1800 \mathrm{~m})$ of new pipe, and it did 
not require connecting approximately 5000 houses. Another factor considered in maintaining the existing system was the potential of missing some sewer connections inadvertently if the whole system was replaced. The two designs are shown in Figure 12.17, which shows the contrast between the two designs.

Using the SWMM program and the related tools to design a sewer system were instrumental to both the design and the analysis. It was estimated that performing this design using hand calculations would have required over 350 sheets of paperwork. Performing the analysis and design using the SWMM program allowed for dynamic viewing and design modifications as the design proceeded. This would not have been practical using hand calculations.
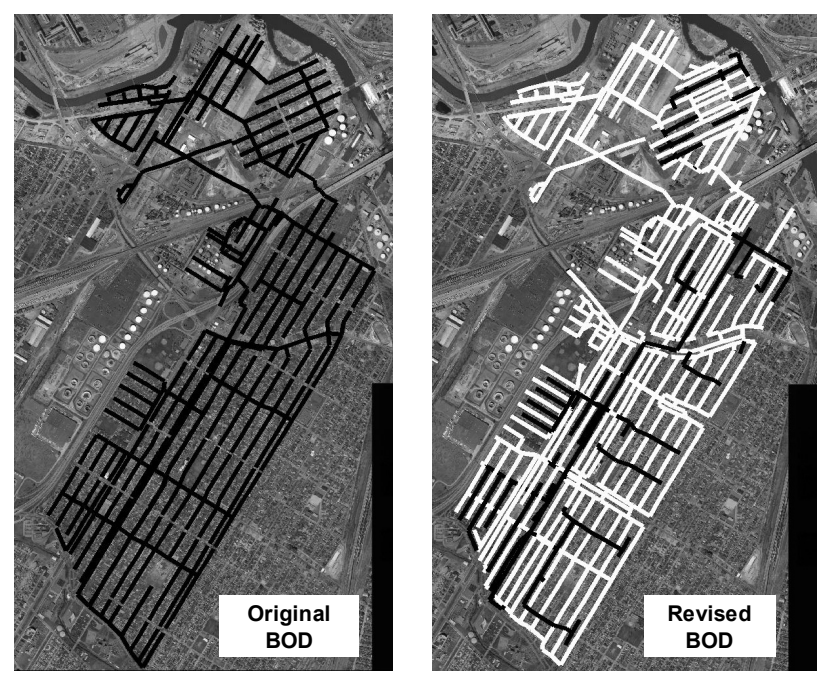

Figure 12.17 Comparison of orignal BOD with revised BOD (existing sewers shown in white and proposed sewers shown in black).

\section{References}

Brink, P., L. Witt, A.A. Ibrahim and C.R. Johnson. 2005. "Flow Needs for City of Detroit Customers through 2050." Journal of Water Management Modeling R223-08. doi: 10.14796/JWMM.R223-08.

Detroit Metro Water Department, General Guidelines for the Design of Lateral Relief Sewers, 1970. 
Huber W.C. and R.E. Dickinson (1988). Storm Water Management Model-Version 4 User's Manual: - Addendum 1 Extran; Cooperative Agreement CR-811607; U.S. EPA; Athens, Georgia.

Sherman, B.J., P. Brink and M.J. TenBroek. 1998. "Spatial and Seasonal Characterization of Infiltration/Inflow for a Regional Sewer System Model." Journal of Water Management Modeling R200-13. doi: 10.14796/JWMM.R200-13.

TenBroek, M.J., G. Fujita, P. Brink, B.J. Sherman and D. White. 1999. "Detroit Water and Sewerage Department Model Extensions and Project Overview." Journal of Water Management Modeling R204-11. doi: 10.14796/JWMM.R204-11. 